\title{
Presentación. El discurso político y literario en las relaciones entre España y Portugal ${ }^{1}$ \\ Presentation. The Political and Literary Discourse in the Relationships between Spain and Portugal
}

\section{Jesús María Usunáriz}

GRISO-Universidad de Navarra

ESPAÑA

jusunariz@unav.es

[Hipogrifo, (issn: 2328-1308), 3.2, 2015, pp. 9-13]

DOI: http://dx.doi.org/10.13035/H.2015.03.02.02

La muerte del rey Don Sebastián tras la fracasada y caótica derrota de Alcazarquivir (1578), la posterior entrada de las tropas de Felipe II en Portugal en 1580 para reivindicar sus derechos dinásticos, fueron los sucesos clave que abrieron una época conocida como la de la «monarquía dual». Esta unión de las coronas se rompería sesenta años más tarde, en 1640, cuando el duque de Braganza, convertido en el rey Juan IV de Portugal, se descubrió como cabeza visible de una sublevación que se mantuvo viva, con sus circunstancias cambiantes, durante veintiocho años, hasta la definitiva firma del tratado de Lisboa de 1668. Por este, se puso fin a los siempre duros y largos años de guerra, se vino a reconocer la plena soberanía del reino de Portugal y quedó sancionada la división peninsular. Aquellas seis décadas de unión no solo contribuyeron a incrementar las ya enormes posesiones territoriales de los Austrias, no solo ayudaron a que los monarcas castellanos pudieran hacer frente a sus enemigos en el norte de Europa, con mayor o menor éxito. Aquellos años fomentaron también el desarrollo de un discurso político, en principio común, y de unas relaciones culturales particularmente estrechas y paralelas. Tan parale-

1. Este monográfico es fruto de la colaboración impulsada desde el proyecto Discurso y poder, lengua y autoridad en el mundo hispánico (siglos XVI-XVII), HAR2012-31536, subvencionado por el Ministerio de Economía y Competitividad. 
las que, tras 1640, y a lo largo de los años, apenas lograron confluir en un punto de encuentro, salvo momentos y autores esporádicos de particular perspicacia.

Sin querer tener la imprudente osadía de pretender llenar un vacío, este monográfico solo desea ofrecer un conjunto de aportaciones a las ya hechas en los últimos años en diferentes ámbitos, que pueda contribuir al impulso de los estudios interdisciplinares en las relaciones entre Portugal y España. Para ello, el denominado Siglo de Oro ocupa un lugar privilegiado a la hora de comprender y estimar las relaciones hispano portuguesas.

En efecto, estos vínculos pasaron por autores como Lope de Vega, Tirso de Molina, Calderón, Jiménez Patón, Ferreira, Faria e Sousa, Botelho, Cordeiro, Pérez Montalbán, Montemayor; por santos portugueses, reyes amantes, monarcas malogrados, cautos secretarios, duques infames, traidores o patriotas, fidalgos y graciosos; a través de la crítica política, del secreto o del engaño, de la risa, el misticismo, el providencialismo, la sensibilidad, la arrogancia, la soberbia o la bipolaridad... Todos ellos, autores, personajes, temas, que están presentes en lo textos que aquí se exponen.

Para lo escritores auriseculares, la historia y las leyendas de la nación portuguesa sirvieron de inspiración continuada en donde la ficción y la realidad formaron una mixtura de gran atractivo. En la mayor parte de los casos, fueron obras imbuidas de una visión «castellano-céntrica», amparada en un pasado común y en una historia compartida tras la unión de las Coronas en 1580 (Domínguez Matito) que desembocó en un periodo de declarada e intensa «lusofilia».

Lope de Vega, por ejemplo, mostraría su admiración por la familia Braganza, y, en general, por el conjunto de la aristocracia lusitana (Álvarez Sellers). De hecho, en los versos que dedicó a los duques de Braganza demostró su admiración por aquella casa nobiliaria y, sobre todo, por el duque Teodosio II, héroe niño en la batalla de Alcazarquivir, casado con la hija del condestable de Castilla y fiel servidor de los Austrias. Dos obras son muestra de ello: La tragicomedia lastimosa del duque de Viseo y El más galán portugués, duque de Berganza. En la primera, una cuestión como la tiranía del rey Juan II y las acciones de su privado, justificaban la rebeldía del duque de Braganza convertido en héroe trágico tras su ejecución en 1483; en la segunda, el personaje protagonizaba la defensa del honor conyugal ante las sospechas de adulterio de su esposa, en una ejemplificante muestra de ejecutor de la imprescindible honra nobiliaria. Todo ello sirvió para lisonjear a una casa nobiliaria imprescindible para el mantenimiento de la unidad de la monarquía (Domínguez Matito).

Esta unidad de las coronas es lo que unos y otros defendieron directa o indirectamente. En El burlador de Sevilla del Tirso de Molina la lusofilia del mercedario parece mostrarse en la descripción idealizada de la ciudad de Lisboa, salida de la boca del personaje don Gonzalo de Ulloa, embajador del rey de Castilla, Alfonso XI, en la primera mitad del siglo XIV, quien calificaba a la urbe portuguesa como «la mayor ciudad de España», término que, en el siglo XVII, venía a apoyar más la causa ibérica (Alexia Dotras). 
En esta línea, el humanista Bartolomé Jiménez Patón, admirador de los autores portugueses, como Ferreira de Vasconcelos, López de Castañeda o Joao de Barros, se mostraba acérrimo defensor de la unidad dinástica, tras la muerte de los reyes don Sebastián y del cardenal Enrique. Unidad amparada en la historia e, incluso, en la supuesta «unidad gramatical» de ambos idiomas. Una defensa que realiza Jiménez Patón a partir de los personajes que aparecen en sus Comentarios de erudición, especialmente un hidalgo portugués defensor de la unidad, o de la descripción que Laminio realiza de la ciudad de Lisboa, quizás como respuesta a un creciente clima de oposición al dominio castellano en la década de los veinte del Seiscientos (Garau).

No debe olvidarse, sin embargo, que autores como Calderón, especialmente en «El príncipe constante o en «A secreto agravio, secreta venganza», o Tirso de Molina en, entre otras muchas, «Las quinas de Portugal», reflejarían, además del recuerdo de hechos históricos de la historia portuguesa, valores más universales como los celos, la venganza o la defensa del honor, al mismo tiempo que construían tópicos como «la arrogancia portuguesa», el fanfarrón castellano, el valor y el apasionamiento de los lusos (Álvarez Sellers). Caracteres estos, presentes también en los entremeses y en los pliegos de villancicos. Es decir, la imagen estereotipada del portugués, con función cómica, «personaje regional» equiparado a otros vasallos de la monarquía hispánica: enamoradizo, amante de la música, arrogante y altivo, cuando no fanfarrón, patriota y antagonista de Castilla (Borrego). Estos autores abordaron también cuestiones teológicas capitales para la doctrina católica, presente siempre en todas ellas, como en la comedia El divino portugués del madrileño Pérez de Montalbán, sobre la vida del santo luso San Antonio de Padua, cuya novedosa estructura es destacada y analizada por J. M. Escudero. Valores éticos que se encuentran presentes también en las Noches claras de Faria e Sousa (Silva Pereira), obra erudita de indudable fin didáctico, en donde se recogen, al igual que en otras producciones del momento de influencia clásica, sentencias, dichos graciosos, citas célebre o hechos extraordinarios.

Por otra parte, fueron varios los autores portugueses que escribieron en lengua castellana. Hoy, en algunos casos, son autores olvidados consecuencia de actitudes ideológicas, difíciles ya de entender. La novela pastoril Diana (1559) del escritor portugués Jorge de Montemayor, sirve a Marta Texeira, en este volumen, para estudiar el bilingüismo «como forma de juego identitario y de reconocimiento estético», esencialmente en la alternancia lingüística de algunos de sus pasajes, en donde el uso del castellano en la descripción bucólica de los campos de Mondego no oculta la proyección simbólica de una Arcadia portuguesa, transmitida, por ejemplo, en las canciones amorosas de las pastoras (Marta Teixeira Anacleto). Otro autor, el prolífico Jacinto Cordeiro, que formó parte también de este grupo de escritores portugueses en lengua castellana, abordaba en su comedia palatina El secretario confuso (1634), la historia de Enrique, secretario, que declaraba abierta y directamente su amor a la princesa de Parma, en una ruptura imprudente y atrevida de las normas sociales, al que seguía un juego enmarañado de silencios, secretos y mentiras, con paralelismos con las obras de Lope o de Tirso (Insúa). 
Mas, si bien se habla de la influencia castellana en la literatura portuguesa del Siglo de Oro, no debe olvidarse que esta influencia no fue unidireccional, como es evidente en la obra de Montemayor (Teixeira). Como ejemplifica Silvina Pereira, Lope de Vega fue un admirador de la figura de Jorge Ferreira de Vasconcelos, lo cual se ve reflejado en las afinidades entre la Eufrosina del portugués (1555) y la Dorotea lopesca (1632), en donde, de nuevo, la inclinación amorosa de los portugueses sale de nuevo a la palestra (Pereira).

No obstante, tras 1640, asistimos a un alejamiento progresivo, al declive de los temas portugueses en la dramaturgia española (Álvarez Sellers), pero no solo. Se constata un giro radical como es evidente en la obra del granadino Álvaro de Cubillo de Aragón, La tragedia del duque de Berganza, en donde, al contrario de la construcción histórica de Lope de Vega, el duque de Braganza deja de ser el héroe trágico enfrentado a la tiranía de Juan II, para convertirse en el ambicioso rebelde contra un rey justo, en un paralelismo evidente con su contemporáneo y su revuelta sediciosa contra Felipe IV (Domínguez Matito).

Así las cosas, las relaciones culturales se mantuvieron no sin dificultades. Es el caso de la figura del poeta portugués en lengua castellana Francisco Botelho de Morais e Vasconcelos (1670-1747), miembro honorario de la Real Academia Española y fundador de la «Adademia dos Unidos» (1730), a pesar de las dificultades y desencuentros diplomáticos (Abreu).

Escollos y fronteras físicas y mentales perduraron hasta tiempos recientes, a pesar, incluso, de la correspondencia permanente en la evolución cultural de ambos países, como, por ejemplo, en el desarrollo por parte de la intelectualidad, portuguesa y española, de un antiaustracismo, palmario en los siglos XVIII y XIX, como nos ha recordado en sus obras el doctor Mainer. Las reticencias y cautelas se observan así en el tratamiento contemporáneo portugués de la citada literatura española del siglo de Oro, como en Las quinas de Portugal, del citado Tirso de Molina. La obra recrea el mito fundador de la nación portuguesa, cuando en 1139, antes de la batalla de Ourique, Cristo se apareció milagrosamente al conde Alfonso Henríquez y le ofreció las llagas de sus manos como símbolo del blasón portugués. Sin embargo, y a pesar de su argumento, sufrió en 1968 la censura salazarista al ver prohibida su presentación en la televisión pública: el texto de un autor español sobre un hito de la historia portuguesa, solo podía ser objeto de desconfianza y de sospecha sobre sus intenciones ocultas (Apolinário).

La distancia, el alejamiento, si bien constatables, no pueden escaparse a la evidencia de la viva existencia de las interacciones de ambos territorios. Ciertamente, la unión tuvo como fruto un capital literario e histórico que solo ideas preconcebidas y de cortos vueltos han intentado ocultar, en medio de una mutua y lamentable desconfianza. Nuestros autores del Siglo de Oro supieron dialogar y reconocerse; ciertamente se rompieron los vínculos políticos pero nunca, al menos del todo, sus lazos culturales. Hay una lectura fundamental, aunque parezca obvia: hay mucho por hacer, mucho por estudiar, por leer, por investigar y descubrir, para conocer mucho mejor una realidad, las de las relaciones políticas, históricas, literarias y cul- 
turales en los siglos XVI, XVII y XVIII, que vaya más allá de tópicos conocidos o de moldes prestablecidos con mayor o menor fundamento. 
